\title{
1 Evidence in Tissint for recent subsurface water on Mars
}

2 Yang Chen ${ }^{\mathrm{a}}$, Yang Liu ${ }^{\mathrm{a}}$, Yunbin Guan ${ }^{\mathrm{b}}$, John M. Eiler ${ }^{\mathrm{b}}$, Chi Ma ${ }^{\mathrm{b}}$, George R. Rossman ${ }^{\mathrm{b}}$,

3 Lawrence A. Taylor ${ }^{\mathrm{c}}$.

4 a: Jet Propulsion Laboratory, California Institute of Technology, Pasadena, CA 91109, USA

5 b: Division of Geological and Planetary Sciences, California Institute of Technology, Pasadena, 6 CA 91125, USA

7 c: Planetary Geosciences Institute, Department of Earth and Planetary Sciences, University of

8 Tennessee, Knoxville, TN 37996, USA

9

10 Submitted to: Earth and Planetary Science Letters

11 Abstract: 262 words

12 Main text: 5916 words

13 Figures: 6

14 Supplementary materials

15

16 Corresponding author

17 Yang Chen

$18 \mathrm{M} / \mathrm{S}$ 183-301

19 Jet Propulsion Laboratory

204800 Oak Grove Dr, Pasadena, CA 91109

21 Email: Yang.Chen@jpl.nasa.gov

22 Telephone: 1-818-354-3194

23 Fax: 1-818-393-4445

24 
Abstract

We report unambiguous chemical evidence for subsurface water activity in the martian crust at $<600 \mathrm{Ma}$ based on the data from Tissint, a fresh martian meteorite fall with minimal terrestrial weathering. The impact-melt pockets in Tissint contain abundant volatiles $\left(\mathrm{H}_{2} \mathrm{O}, \mathrm{CO}_{2}\right.$,

$29 \mathrm{~F}$, and $\mathrm{Cl}$ ), and their concentrations are positively correlated with each other. Higher $\mathrm{H}_{2} \mathrm{O}$ concentrations also accompany higher deuterium contents. These correlations suggest mixing

31 between two volatile sources. The first source is $\mathrm{H}_{2} \mathrm{O}$ in the precursor basalt inherited from

32 martian magma. Magmatic $\mathrm{H}_{2} \mathrm{O}$ in the basalt had low deuterium concentration and was likely

33 stored in the nominally anhydrous minerals. This source contributed little $\mathrm{CO}_{2}$ or halogens to the 34 impact melts. The second source is inferred to be aqueous-alteration products introduced to the 35 basalt by water activity after the basalt erupted. These alteration materials contributed more 36 volatiles to the impact melts than the magmatic source, and had high deuterium abundance, 37 reflecting isotope equilibrium with recent martian atmosphere. The water activities occurred 38 beneath the martian surface after $\sim 600 \mathrm{Ma}$ (crystallization age), but before $\sim 1 \mathrm{Ma}$ (ejection age). 39 The chemical and isotopic signatures of the alteration products in Tissint resemble previously 40 known martian samples associated with old water activities on Mars, which can be traced back to $41 \sim 4.2$ billion years ago (e.g., the mudstone at Gale Crater). This similarity in chemistry and the 42 wide age-span indicate that such water activities were common on Mars throughout its history, 43 which had the potential to form habitable environment. However, the rarity of the volatile-rich 44 zone in Tissint may suggest that recent subsurface-water activities on Mars were limited. 
Plenty of mineralogical and morphological evidence supports the presence of abundant

49 surface and subsurface liquid water on Mars at times >3.6 Ga (e.g., Bibring et al., 2006). At

50 present, the surface of Mars is cold and dry, and water is only stable as ice in the polar regions.

51 However, hydrogen may be bound in surface or subsurface materials at middle to low latitudes

52 (e.g., Bell, 2008; Feldman et al., 2004). As such, it was suggested that after the surface became

53 dry at about 3.6 Ga ago, some water was stored beneath the surface and might form habitable

54 environment (Michalski et al., 2013). However, there are few reports for subsurface liquid water

55 activity on Mars since 3.6 Ga. The seasonal Recurring Slope Lineae (RSL) may be caused by

56 fluid flow, although its exact mechanism is still under debate (McEwen et al., 2011; Ojha et al.,

57 2013).

There has been putative evidence reported in young martian rocks for recent subsurface

59 liquid water, but the chemical signatures of the inferred water sources, particularly their hydrogen isotope compositions, do not completely substantiate this claim. One line of evidence

61 is for evaporates and clay minerals found in veins in three nakhlites (Governador Valadares,

62 Lafayette, and Nakhla), which are inferred to be formed by infiltration of hydrothermal fluids

63 liberated by impact (Bridges and Schwenzer, 2012; Gooding et al., 1991; Treiman et al., 1993);

64 however, the age of the alteration products may be $\sim 670$ Ma or older (Swindle et al., 2000).

65 Noble gas data of the alteration products show martian atmospheric signatures (Swindle et al.,

66 2000), but the hydrogen isotopes of the alteration products show signs of possible terrestrial

67 contamination (Hallis et al., 2012a). Additional reports of carbonate and sulfate in shergottite

68 EETA 79001 (Gooding et al., 1988, 1990) also indicate water activity, but their martian origin is

69 yet to be verified. A second line of evidence comes from Secondary Ion Mass Spectrometry 
(SIMS) measurements of volatile concentrations and hydrogen isotopes in different phases in

71 martian meteorites. Boctor et al. (2003) suggested two hydrogen sources on Mars with

72 contrasting hydrogen isotope compositions. One source is thought to be magmatic water with

73 low $\delta \mathrm{D}$ values, probably a primordial water signature from the martian mantle. The other source

74 is martian surface water and related materials that have exchanged hydrogen isotopes with the

75 martian atmosphere, and hence, have high $\delta \mathrm{D}$ values. However, it is not fully understood how

76 the high $\delta \mathrm{D}$ values in martian meteorites can be related to water activity. Also, the low $\delta \mathrm{D}$

77 signature from martian mantle and terrestrial contributions can be difficult to distinguish. A

78 recent study of three shergottites (EETA79001, LAR06319, and Y-980459) indicated a water

79 source with 1000-2000\%o in $\delta$ D values, which was interpreted as crustal water or ground-ice in

80 sediments on Mars (Usui et al., 2015). The age-span of this water source is bracketed by the

81 crystallization and ejection ages of the three meteorites (472-0.7 Ma). Interaction between

82 martian rocks and ground water was also evoked by Hu et al. (2014), based on zonation of water

83 concentration and hydrogen isotopes in melt inclusions in olivines in shergottite GRV020090.

84 This interaction occurred after the rock crystallized at $196 \mathrm{Ma}$ (Jiang and Hsu, 2012), and the

85 duration of the alteration is estimated to be from a few hundred to a few hundred thousand years

86 based upon diffusion simulations (Hu et al. 2014). However, the $\delta \mathrm{D}$ value of the ground water is

87 inferred to be $\sim 6000 \%$, in contrast to those by Usui et al. (2015).

The variations among the literature may be due to indigenous heterogeneities of water

89 activities on Mars, terrestrial weathering, or laboratory contamination, in some cases. In search

90 of fresh and less-contaminated, constrained chemical signatures of volatile sources on Mars, we

91 have analyzed the impact melts and maskelynites in the Tissint meteorite, the most recent

92 martian meteorite fall with negligible terrestrial weathering. We report the abundances of 
93 volatile $\left(\mathrm{H}_{2} \mathrm{O}, \mathrm{CO}_{2}, \mathrm{~F}, \mathrm{Cl}, \mathrm{S}\right)$ and trace elements ( $\mathrm{Ba}, \mathrm{Y}, \mathrm{Hf}, \mathrm{Nb}$, and rare earth elements), and

94 hydrogen and carbon isotopes. These data are compared with previous studies and Mars

95 exploration missions and provide new constraints on the evolution of martian water and other

96 volatiles.

97 2. Sample and methods

98

99

100

101

102

103

104

105

106

107

108

The Tissint meteorite is a witnessed fall in Morocco that occurred on July 19, 2011

(Chennaoui Aoudjehane et al., 2012). It is an olivine-phyric shergottite with a depleted traceelement pattern (Balta et al., 2015; Chennaoui Aoudjehane et al., 2012), displaying porphyritic basaltic textures without any signs of martian weathering, as has been observed in nakhlites (e.g., Gooding et al., 1991). It has a crystallization age of 600 Ma (Brennecka et al., 2014) and a cosmic-ray exposure age of $\sim 1 \mathrm{Ma}$ (Chennaoui Aoudjehane et al., 2012). This meteorite is highly shocked (e.g., Baziotis et al., 2013; Ma et al., 2015) and contains glassy impact melts up to $\sim 1 \mathrm{~mm}$ in size, ideal for identifying chemical signatures at micrometer-scale using microbeam analytical techniques. Our sample is a $10 \mathrm{~g}$ piece with $\sim 95 \%$ coverage of fusion crust, which was recovered within a few weeks after the observed fall. We investigated two polished sections (UT-1-4 and UT-1-6) mounted in epoxy (EpoThin ${ }^{\mathrm{TM}}$, Buehler).

Impact melts and maskelynites in the Tissint meteorites were analyzed using scanning electron microscopy (SEM, ZEISS 1550VP), electron probe micro-analysis (EPMA, JEOL JXA8200), and Secondary Ion Mass Spectrometry (SIMS). The regions of interest were first inspected under a petrographic microscope and SEM to obtain information on the texture and phase compositions. Volatile concentrations and hydrogen and carbon isotopes were then analyzed using SIMS. The major-element compositions of each SIMS spot were analyzed 
115 afterwards using EPMA. The analytical conditions for EPMA were $15 \mathrm{kV}$ acceleration voltage,

$11610 \mathrm{nA}$ electron beam current, and $5-\mu \mathrm{m}$ beam diameter. For each element, counting times were

$11720 \mathrm{~s}$ on peak and $10 \mathrm{~s}$ on the background.

Abundances of $\mathrm{H}$ (reported as $\mathrm{H}_{2} \mathrm{O}$ ), $\mathrm{C}$ (reported as $\mathrm{CO}_{2}$ ), $\mathrm{F}, \mathrm{Cl}, \mathrm{S}$, and trace elements, and $\mathrm{H}$ and $\mathrm{C}$ isotopes were analyzed with a Cameca IMS 7f-GEO using natural and synthetic

120 glasses as standards. We generally followed previous SIMS analytical procedures

121 (supplementary materials), with efforts particularly aimed to reduce the hydrogen background

122 and to minimize terrestrial contamination. Before SIMS analysis, carbon coating on the samples

123 was removed by gentle polishing, and the samples were cleaned and stored under vacuum at

124 room temperature for a few days. Then, the samples were coated with Au and placed in the

125 high-vacuum $\left(1 \times 10^{-8}\right.$ torr $)$ storage chamber in the SIMS instrument for 2-3 days before analysis.

126 In order to improve the vacuum conditions in the sample chamber and reduce the hydrogen

127 background during analysis, the instrument was baked for at least 12 hours before analysis, and a

128 liquid- $\mathrm{N}_{2}$ cold trap was used during analysis. The vacuum pressure in the sample chamber

129 during analysis was $4 \times 10^{-10}-2 \times 10^{-9}$ torr.

Seven ion species, ${ }^{12} \mathrm{C}^{-},{ }^{16} \mathrm{O}^{1} \mathrm{H}^{-},{ }^{18} \mathrm{O}^{-},{ }^{19} \mathrm{~F}^{-},{ }^{30} \mathrm{Si}^{-},{ }^{32} \mathrm{~S}^{-}$, and ${ }^{35} \mathrm{Cl}^{-}$, were analyzed with a $\mathrm{Cs}^{+}$

131 primary-ion beam, using 2-5 nA beam current and a 15- $\mu \mathrm{m}$ beam diameter. Sample charging

132 was compensated by an electron gun. A mass-resolving power (MRP) of $\sim 5000$ was used to

133 separate ${ }^{16} \mathrm{O}^{1} \mathrm{H}^{-}$from ${ }^{17} \mathrm{O}^{-}$. Ion images of ${ }^{16} \mathrm{O}^{1} \mathrm{H}^{-}$were examined to avoid contamination signals

134 from cracks or holes. Each analysis position was pre-sputtered by the primary beam rastering

135 over a $25 \times 25 \mu \mathrm{m}$ area for 1-2 minutes. The secondary-ion ${ }^{18} \mathrm{O}^{-}$was then automatically centered

136 and mass-calibrated. During analysis, the raster size of the primary-ion beam was reduced to

$13710 \times 10 \mu \mathrm{m}$; a field aperture of $100 \mu \mathrm{m}$ was used; and an electric gate allowed the secondary ions 
138 from the center $8 \times 8 \mu \mathrm{m}$ area to be collected. Each analysis position was analyzed for 20 cycles.

139 In each counting cycle, the counting time was $2 \mathrm{~s}$ for ${ }^{12} \mathrm{C}^{-}$, and 1 second for the others. The ${ }^{18} \mathrm{O}^{-}$

140 counting rate was $6 \times 10^{5}-1 \times 10^{6}$ cps on silicate glasses. A dry olivine standard (GRR1017 with

$141<1 \mathrm{ppm} \mathrm{H}_{2} \mathrm{O}$ ) was used to monitor the $\mathrm{H}_{2} \mathrm{O}$ background during calibration. The ${ }^{16} \mathrm{O}^{1} \mathrm{H}^{-} /{ }^{18} \mathrm{O}^{-}$

142 value on GRR1017 ranged from $5 \times 10^{-4}$ to $2 \times 10^{-3}$, corresponding to 3-10 ppm $\mathrm{H}_{2} \mathrm{O}$ background.

143 This background has been subtracted from the standard data.

Hydrogen and carbon isotopes were analyzed in separate sessions using slightly different

145

146

147

148

149

150

151

152

153

154

155

156 calculated as $\delta \mathrm{D}=\left(\frac{(\mathrm{D} / \mathrm{H})_{\text {sample }}}{(\mathrm{D} / \mathrm{H})_{\text {reference }}}-1\right) * 1000 \%$, where $(\mathrm{D} / \mathrm{H})_{\text {reference }}$ is $1.5576 \times 10^{-4}$ for the

157 Vienna Standard Mean Ocean Water. The $\delta^{13} \mathrm{C}$ values are calculated as

$158 \quad \delta^{13} \mathrm{C}=\left(\frac{\left({ }^{13} \mathrm{C} /{ }^{12} \mathrm{C}\right)_{\text {sample }}}{\left({ }^{13} \mathrm{C} /{ }^{12} \mathrm{C}\right)_{\text {reference }}}-1\right) * 1000 \%$, where $\left({ }^{13} \mathrm{C} /{ }^{12} \mathrm{C}\right)_{\text {reference }}$ is $1.12372 \times 10^{-2}$ for the Vienna

analytical settings. For hydrogen isotope analysis, an MRP of 800 is sufficient and there was no significant ${ }^{1} \mathrm{H}^{2-}$ contribution to ${ }^{2} \mathrm{H}^{-}$. For carbon isotopes, an MRP of 3000 was used to separate ${ }^{13} \mathrm{C}^{-}$from ${ }^{12} \mathrm{C}^{1} \mathrm{H}^{-}$. Ion images of ${ }^{1} \mathrm{H}^{-}$and ${ }^{12} \mathrm{C}^{-}$were examined to avoid spots of anomalously high intensity that likely reflects contamination. After pre-sputtering, the centering of the secondary ion beam and mass calibration for ${ }^{1} \mathrm{H}^{-}$and ${ }^{12} \mathrm{C}^{-}$were manually performed. Each spot was analyzed by $30-100$ cycles depending on the counting rate. In each counting cycle, ${ }^{1} \mathrm{H}^{-}$was counted for $1 \mathrm{~s},{ }^{2} \mathrm{H}^{-}$for $10 \mathrm{~s},{ }^{12} \mathrm{C}^{-}$for $1 \mathrm{~s}$, and ${ }^{13} \mathrm{C}^{-}$for $20 \mathrm{~s}$. The instrument fractionation factors for the ${ }^{1} \mathrm{H}^{-} /{ }^{2} \mathrm{H}^{-}$ratio were 0.91 and 0.95 in two separated analysis sessions. The ${ }^{12} \mathrm{C}^{-} /{ }^{13} \mathrm{C}^{-}$values are reported without correction for the instrument fractionation (standard-less), due to the lack of suitable standard. Since all carbon isotope analyses were performed on one impact melt region in one session, the relative differences in the $\delta^{13} \mathrm{C}$ values are meaningful. The $\delta \mathrm{D}$ values are

159 Pee Dee Belemnite. 
$161 \mathrm{Yb}, \mathrm{Lu}$ ) were analyzed using the energy-filtering technique (supplementary materials). Positive

162 ions of ${ }^{30} \mathrm{Si}$ and the above trace elements were generated by an $\mathrm{O}^{-}$primary ion beam of $20 \mathrm{nA}$

163 and $10 \mu \mathrm{m}$ in diameter. Each analysis position was pre-sputtered by the primary ion beam

164 rastering over a $10 \times 10 \mu \mathrm{m}$ area for 2 minutes. The secondary ion beam and the peak position of

$165{ }^{30} \mathrm{Si}^{+}$were then automatically centered. During analyses, the primary ion beam rastered the

166 center $10 \times 10 \mu \mathrm{m}$ area, and secondary ions from this area were counted without electronic gating.

167 In each counting cycle, the counting time was $1 \mathrm{~s}$ for ${ }^{30} \mathrm{Si}$, and $2-10 \mathrm{~s}$ for the trace-element ions.

168 Each analysis position was analyzed for 5 cycles. Two glass standards from the National

169 Institute of Standards and Technology (NBS610 and NBS612, supplementary materials) were

170 used as trace-elements standards. Uncertainties at $2 \sigma$ relative are $10 \%$ or less for $\mathrm{Ba}, \mathrm{Y}$, and $\mathrm{Dy}$,

171 10-40 \% for Nb, La, Ce, Pr, Nd, Sm, Gd, Tb, Ho, Er, and Yb, 40-50\% for Tm and Lu, and 100-

$172150 \%$ for $\mathrm{Eu}$ and $\mathrm{Hf}$.

After SIMS analysis, each SIMS spot was examined with SEM, and the major-element 174 compositions near each spot were analyzed with the EPMA. Analytical uncertainties $(2 \sigma)$ for 175 the major elements are about 0.7 wt. $\%$ for $\mathrm{SiO}_{2}, 0.3$ wt.\% for $\mathrm{Al}_{2} \mathrm{O}_{3}, \mathrm{FeO}, \mathrm{MgO}$, and $\mathrm{P}_{2} \mathrm{O}_{5}, 0.1$ 176 wt.\% for $\mathrm{TiO}_{2}, \mathrm{MnO}, \mathrm{CaO}, \mathrm{Na}_{2} \mathrm{O}$, and $\mathrm{Cr}_{2} \mathrm{O}_{3}$, and 0.02 wt.\% for $\mathrm{K}_{2} \mathrm{O}$ and $\mathrm{S}$. Analytical 177 uncertainties $(2 \sigma)$ are about $10 \%$ relative for the volatile concentrations, $50-100 \%$ for $\delta \mathrm{D}$ 178 values, and $25 \%$ for $\delta^{13} \mathrm{C}$ (without considering the unknown amount of instrument 179 fractionation). The background levels for $\mathrm{CO}_{2}, \mathrm{H}_{2} \mathrm{O}, \mathrm{F}, \mathrm{Cl}$, and $\mathrm{S}$ are estimated using the lowest 180 concentrations measured in maskelynites near the impact melts in Tissint, which varied slightly 181 for different samples and SIMS sessions. On average, the background levels are 7 ppm for $\mathrm{CO}_{2}$, 18250 ppm for $\mathrm{H}_{2} \mathrm{O}, 1 \mathrm{ppm}$ for $\mathrm{F}$, and $0.2 \mathrm{ppm}$ for $\mathrm{Cl}$ and $\mathrm{S}$. 
184 is a major concern for volatile investigations of samples mounted in epoxy and prepared using

185 water. Terrestrial weathering is negligible in our Tissint sample because of the short residence

186 time (a few weeks) in the dry Moraccan desert. Some researchers have been very cautious and

187 prepared samples without water; nevertheless suspicious contamination signatures may still

188 appear (Usui et al., 2012). We took several precautions to avoid the artifacts of sample

189 contamination during laboratory preparation. First, the contaminants from sample preparation

190 are often concentrated in micro-cracks or cavities, and manifested in very high concentrations of

$191 \mathrm{H}_{2} \mathrm{O}$, carbon, or $\mathrm{Cl}$ coupled with relatively low $\delta \mathrm{D}$ values. Thus, ${ }^{1} \mathrm{H}^{-},{ }^{16} \mathrm{O}^{1} \mathrm{H}^{-}$, and ${ }^{12} \mathrm{C}^{-}$ion

192 images were used to avoid hot spots of hydrogen and carbon. Second, the surface layer exposed

193 to sample preparation was removed by pre-sputtering. Third, every SIMS spot was examined

194 with SEM after SIMS analysis, and the ones with cracks, holes, or possible contaminating

195 minerals, sometimes emerging beneath the original surface, were excluded. Some of these

196 problematic spots yielded abnormally high ${ }^{12} \mathrm{C}$ counts but not for the other volatiles, indicating

197 pure residual carbon coating. Some spots yielded both high ${ }^{12} \mathrm{C}^{-}$and ${ }^{16} \mathrm{O}^{1} \mathrm{H}^{-}$counts, probably

198 reflecting a contaminant different from the carbon coating. None of these spots yielded

199 abnormally high signals for $\mathrm{F}, \mathrm{Cl}$, or $\mathrm{S}$. In addition to sample contamination, SIMS analysis on a

200 mixture of glass and fine crystals, all common textures in the impact melts in martian meteorites,

201 might be affected by unknown matrix effects that bring uncertainties to data reduction and

202 interpretation. Most of the impact-melt pockets in this study are large and glassy, ideal for

203 micro-beam analysis. There are a few SIMS spots covering a mixture of glass and fine crystals

204 as tabulated in Supplementary Table 1a. They are consistent with the data obtained from the 
205 glassy regions, indicating that the matrix effect of the mixture is small. We included these data 206 points in the discussion.

207 3. Results

The major-element compositions of most glassy regions in the impact-melt pockets plot 209 within the whole-rock composition range reported previously (Figs 1a and 1b, Chennaoui

210 Aoudjehane et al., 2012). These regions contain abundant sulfide droplets. Some regions in the 211 melt pockets show large contributions of feldspar components (e.g., >7 wt.\% $\mathrm{Al}_{2} \mathrm{O}_{3}$ ) and contain 212 less sulfide droplets.

The glassy regions in the impact-melt pockets in Tissint contain 8-173 ppm $\mathrm{CO}_{2}, 179$ -

2142388 ppm $\mathrm{H}_{2} \mathrm{O}, 2-87$ ppm F, 1-93 ppm Cl, and 3-4783 ppm S (Fig 2, Supplementary Table 1a).

215 All these concentrations are higher than the estimated backgrounds. One data point (sample\# 1-

216 11, Supplementary Table 1a) yielded anomaly high $\mathrm{CO}_{2}$ concentration (585 ppm). This spot is

217 on a bubble that was initially beneath the polished surface and was excavated by the primary ion

218 beam. Since this bubble was probably completely sealed in the impact glass (no visible cracks),

219 contamination in the bubble is unlikely. There is no anomaly in the other volatile concentrations.

220 To be conservative, we excluded this data point and only discuss the other high $\mathrm{CO}_{2}$

221 concentrations (up to $173 \mathrm{ppm} \mathrm{CO}_{2}$ ). Some SIMS spots contain sulfide droplets and are

222 tabulated in the Supplementary Table 1a. These data points do not show anomalous S

223 concentrations (1104-4529 ppm) compared to the other clean and glassy spots (3-4783 ppm).

224 Only one data point near a series of sulfide droplets (sample\# 10-3) yielded 11,761 ppm S, which 225 is clearly a strong signal from the sulfides. This data point is excluded from the discussion. The 226 volatiles are not correlated with major-element concentrations (Figs 1c and 1d, Supplementary 
227 Table 1a and 2a), but form positive correlations between each other (Fig 2 ). The $\delta \mathrm{D}$ values vary 228 from $45 \%$ o to $4867 \%$, and are negatively correlated with $1 / \mathrm{H}_{2} \mathrm{O}$ (Fig 3). $\mu \mathrm{m}$-wide belt on the polished surface, sandwiched by two glassy regions of impact melts. It

231 contains many small bubbles $(<10 \mu \mathrm{m}$ in diameter), but no big bubbles $(>100 \mu \mathrm{m}$ in diameter $)$ as 232 found in other impact melts in Tissint (e.g., Chennaoui Aoudjehane et al., 2012). The small 233 bubbles can be clearly distinguished from sulfide droplets under transmitted light as they are 234 transparent in the center, while the sulfide droplets are not. Also, some bubbles are exposed on 235 the polished surface. Compared to the adjacent impact-melt regions, $\mathrm{H}_{2} \mathrm{O}$ is about four times 236 higher in this bubbly zone, and $\mathrm{CO}_{2}$ is about seven times higher. It also displays enriched $\mathrm{D}$ and $237{ }^{13} \mathrm{C}$ signals; $\delta \mathrm{D}$ values are higher than the adjacent regions by $\sim 1000 \%$, while $\delta^{13} \mathrm{C}$ by $\sim 40 \%$. 238 Despite all these anomalous volatile signatures, the trace-element concentrations in the bubbly 239 zone are similar to the other impact melts and whole-rock data of Tissint reported by previous 240 studies (Fig 5). We did not observe the enrichment of La, Ce, and $\mathrm{Pr}$ in the impact melts 241 reported by Chennaoui Aoudjehane et al. (2012), similar to Barrat et al. (2014) and Balta et al. 242 (2015).

Maskelynites in Tissint yielded very-low volatile concentrations: 7-20 ppm CO $2,33-339$ 244 ppm $\mathrm{H}_{2} \mathrm{O}, 1-2$ ppm F, 0.2-15 ppm Cl, and 0.1-8.1 ppm S (Supplementary Table 1b). Most of the 245 maskelynite data are at the lower-end of the ranges and are assumed to be background values, to 246 be conservative. Values of $\delta \mathrm{D}$ for maskelynite show a bimodal distribution; most of the data 247 have low $\delta$ D values (from -222 to $296 \%$ ), while three data points have elevated values (1171$2482970 \%$ o). These three points are close to suspected phosphate minerals within maskelynite 
249 (Supplementary Materials), and the $\delta \mathrm{D}$ values may have been affected by the phosphates, which

250 can have different hydrogen isotope composition than maskelynites in the same rock (e.g.,

251 Boctor et al., 2003). One of the three points also has elevated $\mathrm{H}_{2} \mathrm{O}, \mathrm{Cl}$, and $\mathrm{S}$ concentrations that

252 may be contributed by the phosphate nearby. After excluding these three outliers and the

253 background values, it was decided that maskelynites contain less than $111 \mathrm{ppm} \mathrm{H}_{2} \mathrm{O}$, with $\delta \mathrm{D}$

254 values of -222 to $+296 \%$, and no $\mathrm{F}, \mathrm{Cl}$, or $\mathrm{S}$.

255 4. Discussion

256 4.1. Mixing of two end-members

A negative correlation between $\delta \mathrm{D}$ and $1 / \mathrm{H}_{2} \mathrm{O}$ (Fig. 3) is consistent with a mixing

258 between two end-members: a volatile-rich end-member with high $\mathrm{H}_{2} \mathrm{O}$ and $\delta \mathrm{D}$ values, and a

259 volatile-poor end-member with low $\mathrm{H}_{2} \mathrm{O}$ and $\delta \mathrm{D}$ values. This is not consistent with a

260 dehydration trend, which would be a concaved downward in Figure 3 (Hauri et al., 2002), nor

261 consistent with a terrestrial contamination trend, which would point toward terrestrial $\delta \mathrm{D}$ (close

262 to 0 or slightly negative) and high $\mathrm{H}_{2} \mathrm{O}$ concentrations (low $1 / \mathrm{H}_{2} \mathrm{O}$ ). In the following discussion,

263 we first estimate the contribution of each end-member to the impact melts, and then evaluate

264 their possible sources.

A linear regression (the black line in Fig. 3) suggests that the volatile-rich end-member

266 has a $\delta \mathrm{D}$ value of $4600 \pm 600 \%$ (the intercept with the $\delta \mathrm{D}$-axis). Among the different impact

267 melts in Tissint, the bubbly zone is closest to the volatile-rich end-member, because it has the

268 most abundant volatiles and highest $\delta \mathrm{D}$ and $\delta^{13} \mathrm{C}$ values. On the other end, the volatile-poor end-

269 member has $200 \pm 40 \mathrm{ppm}_{2} \mathrm{O}$ (the intercept with $\delta \mathrm{D}=0 \%$ o). This $\mathrm{H}_{2} \mathrm{O}$ concentration depends 
270 on the assumed $\delta \mathrm{D}$ value of the volatile-poor end-member. If the actual $\delta \mathrm{D}$ value is $500 \%$, the

$271 \mathrm{H}_{2} \mathrm{O}$ concentration would be $220 \pm 40 \mathrm{ppm}$.

The proportions of the two end-members in the impact melts can be estimated by a binary

273 mixing calculation along the regression line. We assume that the volatile-rich end-member has 2

274 wt. $\% \mathrm{H}_{2} \mathrm{O}$ with $4600 \%$ in $\delta \mathrm{D}, 0.5$ wt. $\% \mathrm{CO}_{2}$, and 750 ppm Cl (Point A in Figs. 2a and 2b). We

275 assume that the volatile-poor end-member has $200 \mathrm{ppm} \mathrm{H}_{2} \mathrm{O}$ with $0 \%$ in $\delta \mathrm{D}, 15 \mathrm{ppm} \mathrm{CO}_{2}$, and

27610 ppm Cl (Point B in Figs. 2a and 2b). These assumptions are based on the data from Tissint

277 and literature data from other martian samples. The details are discussed in Sections 4.2 and 4.3.

278 The model results suggest that at maximum level (in the bubbly zone), the volatile-rich end-

279 member contributed $\leq 10 \mathrm{wt} \%$ of the impact melts. For the other major and minor elements in

280 the volatile-rich end-member, their abundances would be diluted by a factor of 10 or more, and

281 then mixed with the volatile-poor end-member. If the volatile-rich end-member contained more

282 than 2 wt. $\% \mathrm{H}_{2} \mathrm{O}$, its proportion in the impact melts would be even less, and the dilution factor

283 for other elements would be even larger. Such a dilution effect would hinder the identification of

284 other chemical signatures in this end-member, such as major-element compositions and oxygen 285 fugacity.

\section{4.2. Source for the volatile-rich end-member}

The $\delta \mathrm{D}$ value for the volatile-rich end-member $(4600 \pm 600 \%$ ) indicates that the source

288 exchanged hydrogen isotopes with recent martian atmosphere. This value is consistent with the

289 water released from the Yellowknife Bay mudstone at low temperatures $\left(100-500{ }^{\circ} \mathrm{C}\right)$, but higher

290 than the water released from the mudstone at high temperatures (600-900 ${ }^{\circ} \mathrm{C}$, Mahaffy et al.,

291 2015). The high-temperature water source is interpreted to be the structural hydroxyl in the 
292 smectite in this mudstone, while the low-temperature water source may include later absorbed 293 water (Mahaffy et al. 2015). This value $(4600 \pm 600 \%$ ) is slightly lower than the surface water 294 source inferred by $\mathrm{Hu}$ et al. (2014), but higher than those reported by Usui et al. (2015). It is 295 possible that the martian surface contains heterogeneous water reservoirs due to temporal or 296 spatial evolution of water on Mars. Additionally, magmas with low D/H values could also 297 contribute to the heterogeneities observed in other martian meteorites. 1983), soils (Rao et al., 1999), ground-water or ice (Hu et al., 2014; Usui et al., 2015), or aqueous-alteration products, as observed in nakhlites (Treiman et al., 1995). Bogard and 301 Johnson (1983) suggested direct implantation of martian atmosphere (noble gases, $\mathrm{N}_{2}$, and $\mathrm{CO}_{2}$ ) 302 into meteorites. Later, Bogard and Garrison (1998) championed a slightly different scenario, 303 where martian meteorites (Allan Hills 84001 and nakhlites) could have acquired martian water with dissolved noble gases. For the volatile-rich end-member in Tissint, the martian atmosphere 305 cannot be the sole contributor because of the high abundances of $\mathrm{H}_{2} \mathrm{O}, \mathrm{F}$, and $\mathrm{Cl}$ relative to $\mathrm{CO}_{2}$, 306 which are opposite to the current atmosphere compositions (Mahaffy et al., 2013). meteorites during impact, based on the presence of abundant sulfides and elevated $\mathrm{S}, \mathrm{Ca}, \mathrm{Al}$, and $309 \mathrm{Na}$ in impact melts. There are multiple lines of evidence arguing against this source in Tissint. 310 First, the impact melts did not show the enrichment of $\mathrm{Ca}, \mathrm{Al}$, or $\mathrm{Na}$ compared to the whole-rock 311 composition. In particular, the bubbly zone with the most abundant volatiles and most enriched $312 \mathrm{D}$ and ${ }^{13} \mathrm{C}$ isotopes does not show any anomaly in major-element compositions. Second, the 313 impact melts have high concentrations of $\mathrm{S}$ and abundant sulfide droplets in some regions. 314 However, S concentrations cannot be explained by mixing with martian regolith, because the 
$315 \mathrm{~S} / \mathrm{Cl}$ values are much higher $(>25$, Fig $2 \mathrm{~d})$ than those of the martian surface materials and the 316 alteration veins in nakhlites (Changela and Bridges, 2011; Gooding et al., 1991; Leshin et al., 317 2013; Ming et al., 2014; Treiman et al., 1993; supplementary materials); this suggests that sulfide 318 in the precursor basalt was a major sulfur source to the impact melts. Hence, the high S 319 concentration and abundant sulfide droplets in the impact melts do not reflect a martian regolith 320 component. Furthermore, the impact melts do not show enrichment of light REEs (Balta et al., 321 2015; Barrat et al., 2014; Fig 5), a feature often interpreted as from martian regolith. More 322 broadly, it has been suggested that injection of molten soil into rock within the milli-seconds of 323 impact is difficult (Shaw and Walton, 2013).

A third suggestion involves ground water or ice (Hu et al., 2014; Usui et al., 2015). Hu et al. (2014) proposed a ground-water source with $\sim 6000 \%$ $\delta$ D, and Usui et al. (2015) proposed a 326 ground-water or ice source with 1000-2000\% $\%$ D. Both are different from the $4600 \pm 600 \%$ o

$327 \delta \mathrm{D}$ source in Tissint. Also, the ground water or ice by Usui et al. (2015) was inferred to contain 328 low $\mathrm{Cl}$ concentration, contrary to the positive correlation between $\mathrm{H}_{2} \mathrm{O}$ and $\mathrm{Cl}$ in Tissint.

329 Therefore, a ground-water or ice source is unlikely as the source of the volatile-rich end-member 330 in Tissint.

We suggest that the source for the volatile-rich end-member is, instead, the solid altered 332 materials formed by ground water or ice along grain boundaries, vesicles, or cracks in the 333 precursor rock. The bubbly zone, with the most abundant volatiles and high $\delta \mathrm{D}$ and $\delta^{13} \mathrm{C}$ values, 334 has similar major-element compositions to the surrounding impact melts and the bulk Tissint, a 335 feature observed previously for nakhlites (iso-chemical weathering; Ming et al., 2008; Treiman 336 et al., 1993). This feature indicates a small water-rock ratio, such that the whole system did not 
337 undergo extensive leaching and was closed or nearly closed for the major elements, but was open

338 for the addition of volatiles (Ming et al., 2008).

The positive correlations among $\mathrm{H}_{2} \mathrm{O}, \mathrm{F}, \mathrm{Cl}$, and $\mathrm{CO}_{2}$ suggest the water may have

340 precipitated halogen salts and carbonate. The relatively high $\delta^{13} \mathrm{C}$ values of the bubbly zone,

341 together with the high $\delta \mathrm{D}$ values and high volatile concentrations, indicate an indigenous martian

342 carbon source in the bubbly zone. The standard-less value of $22 \% \circ \delta^{13} \mathrm{C}$ of the bubbly zone is

343 consistent with the carbon component released from whole-rock Tissint at $1100{ }^{\circ} \mathrm{C}$ (Chennaoui

344 Aoudjehane et al., 2012), and is also consistent with the high-temperature carbon component

345 released from martian surface materials measured by Curiosity (up to $20 \%$ $\delta^{13} \mathrm{C}$, Leshin et al.,

346 2013). It is lower than the current martian atmosphere value of $46 \%$ (Mahaffy et al., 2013).

347 However, the above comparisons are not rigorous, because of the unknown instrumental-

348 fractionation factor.

The actual volatile concentrations in the alteration products in Tissint cannot be inferred

350 directly from the data, because of the unknown amount of dilution during impact melting and

351 mixing. Instead, comparisons are made for the volatile ratios of different samples assuming that

352 the volatiles are not significantly fractionated during the formation of the impact melts. The

353 presence of bubbles in the impact melts (not limited to the bubbly zone) could cause volatile

354 fractionation because they partition differently between gas and silicate melts, but their behavior

355 is not fully understood. Nonetheless, the data suggest this effect is small. The linear correlation

356 between $\mathrm{H}_{2} \mathrm{O}$ and $\mathrm{Cl}$ argues against degassing (or in-gassing) because $\mathrm{H}_{2} \mathrm{O}$ would be lost more

357 readily than $\mathrm{Cl}$. Furthermore, $\mathrm{H}_{2} \mathrm{O}$ concentrations and $\delta \mathrm{D}$ values do not display significant

358 dehydration effects (i.e., the most mobile species was not lost by degassing during impact). 
Also, the time scale for the impact-melt formation is exceptionally short for diffusion (Shaw and Walton 2013). Therefore, we infer that the volatile ratios in the impact melts were not significantly changed from the ratios in the precursor alteration products.

Here, we compare the volatile ratios in the bubbly zone, which best represent the volatilerich end-member, to the other known martian surface-volatile reservoirs. Aqueous-alteration

364 products have been reported in nakhlites (e.g., Treiman et al., 1993), and volatile concentrations 365 in the surface rocks on Mars have been directly measured (Leshin et al., 2013; Ming et al., 2014; supplementary materials). The $\mathrm{H}_{2} \mathrm{O} / \mathrm{CO}_{2}$ values of the bubbly zone (4-18) overlap with that of the mudstone at Yellowknife Bay (Ming et al., 2014), but are slightly higher than that in the aeolian fines at Rocknest (Leshin et al., 2013, Fig 2a). The $\mathrm{H}_{2} \mathrm{O} / \mathrm{Cl}$ value (25-35) is also similar to that of the mudstone at Yellowknife Bay, but slightly higher than that in the other martian surface materials (Fig 2b). The alteration veins in nakhlites have a broad range of $\mathrm{H}_{2} \mathrm{O} / \mathrm{Cl}$ values 371 from 20 to 700 (Changela and Bridges, 2011; Gooding et al., 1991; Treiman et al., 1993), which 372 brackets the values of the bubbly zone in Tissint. The broad range of $\mathrm{H}_{2} \mathrm{O} / \mathrm{Cl}$ is because the $\mathrm{H}_{2} \mathrm{O}$ 373 concentrations in the alteration veins were not accurately determined but inferred by the 374 difference from $100 \%$ total oxide concentrations. In summary, the $\mathrm{H}_{2} \mathrm{O} / \mathrm{CO}_{2}$ and $\mathrm{H}_{2} \mathrm{O} / \mathrm{Cl}$ values 375 in the volatile-rich source in Tissint are best matched by those in the mudstone at Yellowknife 376 Bay, while the alteration products in nakhlites and martian surface materials also contain similar 377 amount of volatiles with slightly different ratios. The formation of the alteration products in Tissint can be broadly bracketed to be in the 379 late Amazonian, between its crystallization age of $~ 600 \mathrm{Ma}$ (Brennecka et al., 2014) and its 380 cosmic-ray exposure age of $\sim 1$ Ma (Chennaoui Aoudjehane et al., 2012). Moreover, the young cosmic-ray exposure age of Tissint suggests that the rock resided at least a few meters below the 
martian surface before the impact launch (Warren, 1994). Combined, the alteration products recorded in Tissint are associated with subsurface water activity in the late Amazonian. Such water activities have been suggested by Hu et al. (2014) and Usui et al. (2015). The high concentrations of $\mathrm{CO}_{2}, \mathrm{~F}$, and $\mathrm{Cl}$ in the alteration products suggest that the water dissolved significant amounts of halogen salts and carbonates (i.e., saline or brine water), which is similar to the inferred water activities responsible for the alteration products in the nakhlites (Treiman et al., 1993). The rarity of such a bubbly zone in Tissint implies the water activity was limited (local and transient). Given the late-Amazonian water activity in Tissint, the $\sim 670 \mathrm{Ma}$ or older alteration products in nakhlites (Swindle et al., 2000), and the $\sim 3$ Ga mudstone at Yellowknife Bay (Grant et al., 2014), saline or brine water activities beneath the martian surface may have persisted from early history to the present day.

\subsection{Volatile-poor end-member and its source}

The low $\delta \mathrm{D}$ value in the volatile-poor end-member in Tissint is consistent with the inferred hydrogen-isotope composition of the martian mantle (Boctor et al., 2003; Hallis et al., 2012b; Leshin et al., 1996; Usui et al., 2012); this indicates that the source is the precursor basalt that inherited the hydrogen-isotope signature from the martian mantle. The inference on the water content of this end-member depends on the corresponding $\delta \mathrm{D}$ value. Assuming a $\delta \mathrm{D}$ value of $0 \%$, water content of this end-member is $200 \pm 40 \mathrm{ppm}$ (Fig 3).

The source for the volatile-poor end-member is the pre-impact, non-altered portion of the basalt, and is most likely the nominally anhydrous minerals (NAMs, i.e., olivine, pyroxene, and plagioclase) in the original basalt, because there is no report of hydrous minerals (apatite in particular) in Tissint (Balta et al., 2015). It is well known that NAMs on Earth can store up to a few hundred ppm of $\mathrm{H}_{2} \mathrm{O}$ as $\mathrm{OH}$ (e.g., Bell and Rossman, 1992). However, analysis for $\mathrm{H}_{2} \mathrm{O}$ in 
405 NAMs in martian meteorites is limited, and the data vary from 0 to 1000 ppm (Boctor et al., 406 2003; McCubbin et al., 2014; Usui et al., 2015). The volatile-poor end-member inferred from

407 the impact melts could serve as a proxy for the $\mathrm{H}_{2} \mathrm{O}$ in bulk sample (mainly NAMs) before

408 impact (detail in section 4.4), which in turn could be an indicator of the magmatic-water content.

409 Such an approach is independent and complementary to the other magmatic-water proxies, such

410 as melt inclusions and hydrous phases (amphiboles and apatites; Boyce et al., 2014; Greenwood

411 et al., 2008; Pernet-Fisher et al., 2014).

\section{4.4. Water in the nominally anhydrous minerals}

The scatter in the correlation between $\delta \mathrm{D}$ and $1 / \mathrm{H}_{2} \mathrm{O}$ is non-negligible (Fig 3), reflecting

414 that each melt pocket represents melting and mixing of different amounts of host minerals

415 (olivine, pyroxene and plagioclase). Thus, the two end-member mixing scenario (volatile-rich

416 and volatile-poor) is in fact a four end-member mixing scenario (volatile-rich, olivine, pyroxene,

417 and plagioclase). For a better assessment of pre-impact $\mathrm{H}_{2} \mathrm{O}$ contents in NAMs, we conducted a

418 2-step calculation, assuming that the alteration products in different impact melts have the same

$419 \mathrm{H}_{2} \mathrm{O}$ concentration and $\delta \mathrm{D}$ value. We have estimated the $\mathrm{H}_{2} \mathrm{O}$ stored in the Tissint NAMs using

420 a two-step model. First, for each impact-melt pocket that has more than one data point of $\delta \mathrm{D}$, a

421 straight line was fitted to its $\delta \mathrm{D}-1 / \mathrm{H}_{2} \mathrm{O}$ trend, with a fixed intercept at $\delta \mathrm{D}$ axis $(4600 \%$ ). The

$422 \mathrm{NAM} \mathrm{H}_{2} \mathrm{O}$ concentrations for each pocket were inferred by extrapolating the fit to $\delta \mathrm{D}=0 \%$ o

423 (Fig 6a). Second, the inferred $\mathrm{NAM} \mathrm{H}_{2} \mathrm{O}$ concentrations were plotted against the major-element 424 concentrations of the corresponding impact melts to display the approximate mixing trends (Figs $4256 b, c$, and d). 
In detail, the intercepts from different pockets to the $\delta \mathrm{D}$-axis vary from 4500 to $5500 \%$,

427 which is consistent with the hydrogen-isotope compositions of martian surface materials (Leshin

428 et al., 2013). We further refined the model by fixing the intercepts at $4600 \%$ $\delta \mathrm{D}$ (Fig 6a) to

429 fulfill the assumption that all alteration products share the same $\delta \mathrm{D}$ value and to be consistent

430 with the linear regression of the whole data set (Fig 3). With this fixation, the $\mathrm{NAM}_{2} \mathrm{O}$

431 concentrations decrease slightly. The NAM $\mathrm{H}_{2} \mathrm{O}$ contents also depend on the assumed NAM $\delta \mathrm{D}$

432 values. Using $\delta \mathrm{D}=500 \%$ instead of $0 \%$, the $\mathrm{NAM} \mathrm{H}_{2} \mathrm{O}$ contents would increase by $10 \%$.

433 Using $\delta \mathrm{D}=-500 \%$, the $\mathrm{NAM} \mathrm{H}_{2} \mathrm{O}$ contents would decrease by $8 \%$. Regardless of these

434 different model parameters, the mixing trends shown in Fig 6 are similar.

The modeling results show that different impact melts contained different contributions

436 from olivine, pyroxene, and plagioclase (Fig. 6). The $\mathrm{SiO}_{2}$ concentration in the impact melts

437 distinguishes the olivine component ( $\left.37 \mathrm{wt} . \% \mathrm{SiO}_{2}\right)$ from pyroxene and plagioclase ( 53 wt.\%

$438 \mathrm{SiO}_{2}$ ), while the $\mathrm{Al}_{2} \mathrm{O}_{3}$ concentration, labelled near each data point, further distinguishes

439 plagioclase $\left(\mathrm{Al}_{2} \mathrm{O}_{3}\right.$ up to $\left.27 \mathrm{wt} . \%\right)$ from pyroxene (low $\mathrm{Al}_{2} \mathrm{O}_{3}$ close to 4 wt.\%). For the impact

440 melts with low $\mathrm{Al}_{2} \mathrm{O}_{3}$ concentrations ( 4 wt \%), the $\mathrm{NAM} \mathrm{H}_{2} \mathrm{O}$ and $\mathrm{SiO}_{2}$ concentrations form a

441 positive correlation, demonstrating the mixing between olivine and pyroxene. Extrapolating this

442 trend to the pyroxene and olivine compositions suggests 500-600 ppm $\mathrm{H}_{2} \mathrm{O}$ in pyroxene and 0

443 ppm $\mathrm{H}_{2} \mathrm{O}$ in olivine. For the impact melts with high $\mathrm{Al}_{2} \mathrm{O}_{3}$ concentrations $(>7 \mathrm{wt} \%), \mathrm{NAM} \mathrm{H}_{2} \mathrm{O}$

444 and $\mathrm{SiO}_{2}$ concentrations form a negative correlation, demonstrating the contribution from

445 plagioclase. Extrapolating the negative trend to the plagioclase composition suggests 0-100 ppm

$446 \mathrm{H}_{2} \mathrm{O}$ in plagioclase. Similar features can be observed for $\mathrm{FeO}$ and $\mathrm{Al}_{2} \mathrm{O}_{3}$ (Fig 6c and 6d) and

447 other major components, but not for $\mathrm{P}_{2} \mathrm{O}_{5}$ (Fig 6e). 
The estimated 0-100 ppm $\mathrm{H}_{2} \mathrm{O}$ in plagioclases is consistent with the data in the

449

450

451

452

453

454

455

456

457

458

459

maskelynites measured in this study (Supplementary Table 1b), suggesting that the maskelynites did not gain much $\mathrm{H}_{2} \mathrm{O}$ during the impact. Literature data on olivines and pyroxenes are limited and scattered. Boctor et al. (2003) reported up to 88 ppm $\mathrm{H}_{2} \mathrm{O}$ in olivines and $3360 \mathrm{ppm}_{2} \mathrm{O}$ in pyroxenes in shergottites and chassignite (EETA 79001, ALHA 77005, Shergotty, Zagami, Chassigny). The model $\mathrm{H}_{2} \mathrm{O}$ concentrations in this study fall within literature data range.

The correlation in Figure 6 also argues against terrestrial contamination or impact degassing, because these processes would affect the $\mathrm{H}_{2} \mathrm{O}$ concentrations and hydrogen isotopes regardless of the major-element compositions of the impact melts. Lastly, the $\mathrm{NAM} \mathrm{H}_{2} \mathrm{O}$ content does not correlate with $\mathrm{P}_{2} \mathrm{O}_{5}$ concentrations, consistent with the absence of hydrous apatite in Tissint.

\section{Conclusion}

The impact-melt pockets in Tissint contain abundant volatiles that are positively correlated: 8-173 ppm $\mathrm{CO}_{2}, 179-2388$ ppm $\mathrm{H}_{2} \mathrm{O}, 2-87$ ppm F, 1-93 ppm Cl, and 3-4783 ppm S. The $\delta \mathrm{D}$ values vary from $45 \%$ o to $4867 \%$, and are also positively correlated with $\mathrm{H}_{2} \mathrm{O}$ concentrations. These data suggest mixing during impact between two martian volatile sources: magmatic volatiles and aqueous alteration products. The magmatic volatiles are stored in the nominally anhydrous minerals in Tissint, with an average of $200 \mathrm{ppm} \mathrm{H}_{2} \mathrm{O}$. The inferred alteration products have $\mathrm{H}_{2} \mathrm{O} / \mathrm{CO}_{2}$ and $\mathrm{H}_{2} \mathrm{O} / \mathrm{Cl}$ values similar to the other martian materials associated with ancient aqueous activities on Mars. The aqueous alteration occurred after the crystallization of Tissint at $\sim 600 \mathrm{Ma}$. Combined, these data suggest common water activities on 
469 Mars during its entire history, but at a smaller scale for younger, late Amazonian rocks, on the 470 basis of the low water-rock ratios. 


\section{Acknowledgements}

472 Authors Y.C. \& Y.L. are supported by the Jet Propulsion Laboratory, which is managed by the 473 California Institute of Technology under a contract with NASA. We thank Chris Webster for his 474 comments on an earlier draft. We thank Tamsin Mather, Tomohiro Usui, and one anonymous 475 reviewer for their constructive comments. This work was funded by NASA Cosmochemistry 476 grants NNX11AG58G to L.A.T. and NNN13D465T to Y.L. Funding from NSF grant EAR4771322082 is acknowledged by G.R.R. The EPMA and SEM were performed at the Caltech 478 Geological and Planetary Science Division Analytical Facility, which is supported in part by 479 NSF grants EAR-0318518 and DMR-00800065. Analysis by SIMS was done at the Caltech 480 Microanalysis Center that is partially supported by the Gordon and Betty Moore Foundation. 


\section{Reference}

1. Balta JB, Sanborn M, Udry A, Wadhwa M, McSween HY (2015) Petrology and trace element geochemistry of Tissint, the newest shergottite fall. Meteorit. Planet. Sci. 50, 63-85.

2. Barrat JA, Jambon A, Ferriere L, Bollinger C, Langlade JA, Liorzou C, Boudouma O, Fialin M (2014) No martian soil component in shergottite meteorites. Geochim. Cosmochim. Acta 125, 23-33.

3. Baziotis IP, Liu Y, DeCarli PS, Melosh HJ, McSween HY, Bodnar RJ, Taylor LA (2013) The Tissint martian meteorite as evidence for the largest impact excavation. Nature Communications, doi:10.1038/ncomms2414.

4. Bell DR, Rossman GR (1992) Water in Earth's mantle: The role of nominally anhydrous minerals. Science 255, 1391-1397.

5. Bell J (2008) The Martian Surface, Composition, Mineralogy, and Physical Properties. Cambridge University Press, New York.

6. Bibring J-P, Langevin Y, Mustard JF, et al. (2006) Global mineralogical and aqueous Mars history derived from OMEGA/Mars Express data. Science 312, 400, doi:10.1126/science.1122659.

7. Bogard DD, Johnson P (1983) Martian gases in an Antarctic meteorite? Science 221, 651654.

8. Bogard DD, Garrison DH (1998) Relative abundances of argon, krypton, and xenon in the Martian atmosphere as measured in Martian metorites. Geochim. Cosmochim. Acta 62, 1829-1835.

9. Boctor NZ, Alexander CMO'D, Wang J, Hauri E (2003) The sources of water in Martian meteorites: clues from hydrogen isotopes. Geochim. Cosmochim. Acta 67, 3971-3989.

10. Boyce JW, Tomlinson SM, McCubbin FM, Greenwood JP, Treiman AH (2014) The lunar apatite paradox. Sciencexpress, doi:10.1126/science.1250398.

11. Brennecka GA, Borg LE, Wadhwa M (2014) Insights into the Martian mantle: The age and isotopics of the meteorite fall Tissint. Meteorit. Planet. Sci. 49, 412-418.

12. Bridges JC, Schwenzer SP (2012) The nakhlite hydrothermal brine on Mars. Earth Planet. Sci. Lett. 359-360, 117-123, doi:10.1016/j.epsl.2012.09.044.

13. Changela HG, Bridges JC (2011) Alteration assemblages in the nakhlites: Variation with depth on Mars. Meteorit. Planet. Sci. 45, 1847-1867.

14. Chennaoui Aoudjehane H, Avice G, Barrat JA et al. (2012) Tissint martian meteorite: A fresh look at the interior, surface, and atmosphere of Mars. Science 338, 785-788.

15. Feldman WC, Prettyman TH, Maurice S, Plaut JJ, Bish DL, et al. (2004) Global distribution of near-surface hydrogen on Mars. J. Geophys. Res. 109, doi:10.1029/2003JE002160.

16. Gooding JL, Wentworth SJ, Zolensky ME (1988) Calcium carbonate and sulfate of possible extraterrestrial origin in the EETA 79001 meteorite. Geochim. Cosmochim. Acta 52, 909915.

17. Gooding JL, Aggrey KE, Muenow DW (1990) Volatile compounds in shergottites and nakhlite meteorites. Meteorit. Planet. Sci. 25, 281-289. 
18. Gooding JL, Wentworth SJ, Zolensky ME (1991) Aqueous alteration of the Nakhla meteorite. Meteorit. Planet. Sci. 26, 135-143.

19. Grant JA, Wilson SA, Mangold N, Calef III F, Grotzinger JP (2014) The timing of alluvial activity in Gale crater, Mars. Geophys. Res. Lett. 41, 1142-1148, doi:10.1002/2013GL058909.

20. Greenwood JP, Itoh S, Sakamoto N, Vicenzi EP, Yurimoto H (2008) Hydrogen isotope evidence for loss of water from Mars through time. Geophys. Res. Lett. 35, L05203, doi:10.1029/2007GL032721.

21. Hallis LJ, Taylor GJ, Nagashima K, Huss GR, Needham AW, Grady MM, Franchi IA (2012a) Hydrogen isotope analyses of alteration phases in the nakhlite martian meteorites. Geochim. Cosmochim. Acta 97, 105-119.

22. Hallis LJ, Taylor GJ, Nagashima, K, Huss GR (2012b) Magmatic water in the martian meteorite Nakhla. Earth Planet. Sci. Lett. 359-360, 84-92.

23. Hauri E (2002) SIMS analysis of volatiles in silicate glasses, 2: Isotopes and abundances in Hawaiian melt inclusions. Chem. Geol. 183, 115-141.

24. Hu S, Lin Y, Zhang J, Hao J, Feng L, Xu L, Yang W, Yang J (2014) NanoSIMS analyses of apatite and melt inclusions in the GRV 020090 Martian meteorite: Hydrogen isotope evidence for recent past underground hydrothermal activity on Mars. Geochim. Cosmochim. Acta $140,321-333$.

25. Jiang Y, Hsu W (2012) Petrogenesis of Grove Mountains 020090: An enriched "lherzolitic" shergottite. Meteorit. Planet. Sci. 47, 1419-1435, doi:10.1111/j.1945-5100.2012.01404.x.

26. Leshin LA, Epstein S, Stolper EM (1996) Hydrogen isotope geochemistry of SNC meteorites. Geochim. Cosmochim. Acta 60, 2635-2650.

27. Leshin LA, Mahaffy PR, Webster CR et al. (2013) Volatile, isotope, and organic analysis of martian fines with the Mars Curiosity rover. Science 341, doi:10.1126/science.1238937.

28. Ma C, Tschauner O, Beckett JR, Liu Y, Rossman GR, Zhuravlev K, Prakapenka V, Dera P, Taylor LA (2015) Tissintite, (Ca,Na,[])AlSi ${ }_{2} \mathrm{O}_{6}$, a highly-defective, shock-induced, highpressure clinopyroxene in the Tissint martian meteorite. Earth Planet. Sci. Lett. doi:10.1016/j.epsl.2015.03.057

29. Mahaffy PR, Webster CR, Atreya SK et al. (2013) Abundance and Isotopic Composition of Gases in the Martian Atmosphere from the Curiosity Rover. Science 341, 263-266.

30. Mahaffy PR, Webster CR, Stern JC et al. (2015) The imprint of atmospheric evolution in the D/H of Hesperian clay minerals on Mars. Science 347, 412-414.

31. McEwen AS, Ojha L, Dundas CM, et al. (2011) Seasonal flows on warm martian slopes. Science 333, 740, doi:10.1126/science.1204816.

32. Michalski JR, Cuadros J, Niles PB, Parnell J, Rogers AD, Wright SP (2013) Groundwater activity on Mars and implications for a deep biosphere. Nature Geoscience, 6, 133-138, doi:10.1038/ngeo1706.

33. Ming DW, Morris RV, Clark BC (2008) Aqueous alteration on Mars. In The Martian Surface: Composition, Mineralogy, and Physical Properties (JF Bell III, ed.), Cambridge University Press. 
34. Ming DW, Archer Jr. PD, Glavin DP, et al. (2014) Volatile and organic compositions of sedimentary rocks in Yellowknife Bay, Gale Crater, Mars. Science 343, doi:10.1126/science.1245267.

35. Ojha L, Wray JJ, Murchie SL, McEwen AS, Wolff MJ, Karunatillake S (2013) Spectral constraints on the formation mechanism of recurring slope lineae. Geophys. Res. Lett. 40, 5621-5626, doi:10.1002/2013GL057893.

36. Pernet-Fisher JF, Howarth GH, Liu Y, Chen Y, Taylor LA (2014) Estimating the lunar mantle water budget from phosphates: Complications associated with silicate-liquidimmiscibility. Geochim. Cosmochim. Acta 144, 326-341, doi:10.1016/j.gca.2014.09.004.

37. Rao MN, Borg LE, McKay DS, Wentworth SJ (1999) Martian soil component in impact glasses in a martian meteorite. Geophys. Res. Lett. 26, 3265-3268.

38. Shaw CSJ, Walton E (2013) Thermal modeling of shock melts in martian meteorites: implications for preserving martian atmospheric signatures and crystallization of highpressure minerals from shock melts. Meteorit. Planet. Sci. 48, 758-770.

39. Swindle TD, Treiman AH, Lindstrom DJ, Burkland MK, Cohen BA, Grier JA, Li B, Olson EK (2000) Noble gases in iddingsite from the Lafayette meteorite: Evidence for liquid water on Mars in the last few hundred million years. Meteorit. Planet. Sci. 35, 107-115, doi:10.1111/j.1945-5100.2000.tb01978.x.

40. Treiman AH, Barrett RA, Gooding JL (1993) Preterrestrial aqueous alteration of the Lafayette (SNC) meteorite. Meteorit. Planet. Sci. 28, 86-97.

41. Usui T, Alexander CM O'D, Wang J, Simon J, Jones JH (2012) Origin of water and mantlecrust interactions on Mars inferred from hydrogen isotopes and volatile element abundances of olivine-hosted melt inclusions of primitive shergottites. Earth Planet. Sci. Lett. 357-358, 119-129.

42. Usui T, Alexander CM O'D, Wang J, Simon JI, Jones JH (2015) Meteoritic evidence for a previously unrecognized hydrogen reservoir on Mars. Earth Planet. Sci. Lett. 410, 140-151. 43. Warren PH (1994) Lunar and martian meteorite delivery services. Icarus 111, 338-363. 
Figure captions

592 Figure 1. Major-element and volatile concentrations of the impact melts in Tissint. $\mathbf{a}$ and $\mathbf{b}$ : The 593 major-element composition of the impact melts can be explained by mixing of olivine, pyroxene, 594 and plagioclase in the precursor basalt. The bubbly zone that has the most abundant volatiles 595 does not show an anomaly in major-element composition. $\mathbf{c}$ and $\mathbf{d}: \mathrm{H}_{2} \mathrm{O}$ and $\mathrm{SiO}_{2}$, and $\mathrm{H}_{2} \mathrm{O}$ and $596 \quad \mathrm{P}_{2} \mathrm{O}_{5}$ concentrations are not correlated.

597

598

Figure 2. Volatiles in the impact melts in Tissint and comparison to other martian materials

599 (plotted in fields, references in the supplementary materials). Concentrations of $\mathrm{H}_{2} \mathrm{O}, \mathrm{CO}_{2}, \mathrm{Cl}$, 600 and $\mathrm{F}$ are positively correlated. The black solid lines represent calculated mixing trends between two volatile end-members, and each dot on the line marks a $10 \%$ mixing interval.

602

603

Figure 3. Negative correlation between $\delta \mathrm{D}$ and $1 / \mathrm{H}_{2} \mathrm{O}$, consistent with mixing between two $\mathrm{H}_{2} \mathrm{O}$

604 end-members. Point A represents the volatile-rich end-member, with a $\delta \mathrm{D}$ value of $4600 \pm 600$

$605 \%$ (the intercept with the $\delta \mathrm{D}$-axis). Point B represents the volatile-poor end-member, with $200 \pm$ $60640 \mathrm{ppm} \mathrm{H}_{2} \mathrm{O}$ (the intercept with $\delta \mathrm{D}=0 \%$ ). The effects of terrestrial contamination and 607 dehydration are schematically shown, and there are no indications of these effects. The fitting 608 line is $\delta \mathrm{D}=-900,000 / \mathrm{H}_{2} \mathrm{O}+4600$, where $\mathrm{H}_{2} \mathrm{O}$ is in ppm, with $\mathrm{R}^{2}=0.61$. The deviation from 609 this trend is discussed in Section 4.4. The hydrogen-isotope data for the mudstone are from 610 Mahaffy et al. (2015).

611

612 Figure 4. The most volatile-rich region in the impact melts in Tissint (the bubbly zone). a:

613 Back-scattered electron (BSE) and transmitted-light images showing the bubbly zone between 
614 the two dashed lines. The black rectangle box indicates the area of the transmitted light image.

615 This zone has higher $\delta \mathrm{D}$ and $\delta^{13} \mathrm{C}$ values than the adjacent regions. b \& c: This zone also has 616 high $\mathrm{H}_{2} \mathrm{O}$ and $\mathrm{CO}_{2}$ concentrations.

617

618 Figure 5. Concentrations of CI-chondrite normalized trace-element concentrations in the bubbly 619 impact-melt zone, and comparison to other impact melts and whole-rock data of Tissint. The 620 whole-rock data are from Chennaoui Aoudjehane et al. (2012) and Balta et al. (2015).

621

622 Figure 6. Water in the nominally anhydrous minerals in Tissint. a: For each impact melt, 623 extrapolating the $\delta \mathrm{D}-1 / \mathrm{H}_{2} \mathrm{O}$ trend to $\delta \mathrm{D}=0 \%$ o to infer the $\mathrm{NAM} \mathrm{H}_{2} \mathrm{O}$ content. b, $\mathbf{c}$ and d: The 624 inferred $\mathrm{NAM} \mathrm{H} \mathrm{H}_{2} \mathrm{O}$ content correlates with $\mathrm{SiO}_{2}, \mathrm{FeO}$, and $\mathrm{Al}_{2} \mathrm{O}_{3}$ concentrations of the impact 625 melts, suggesting 400-500 $\mathrm{ppm}_{2} \mathrm{O}$ in pyroxene, 0-100 ppm $\mathrm{H}_{2} \mathrm{O}$ in plagioclase, and dry 626 olivine. In sub-figures $\mathbf{b}$ and $\mathbf{c}$, the number labelled near each symbol indicates the $\mathrm{Al}_{2} \mathrm{O}_{3}$ 627 concentration of each impact melt. In sub-figure $\mathbf{d}$, the number near each symbol indicates the 628 corresponding $\mathrm{SiO}_{2}$ concentration. e: the highest $\mathrm{H}_{2} \mathrm{O}$ content is not related to high $\mathrm{P}_{2} \mathrm{O}_{5}$. 

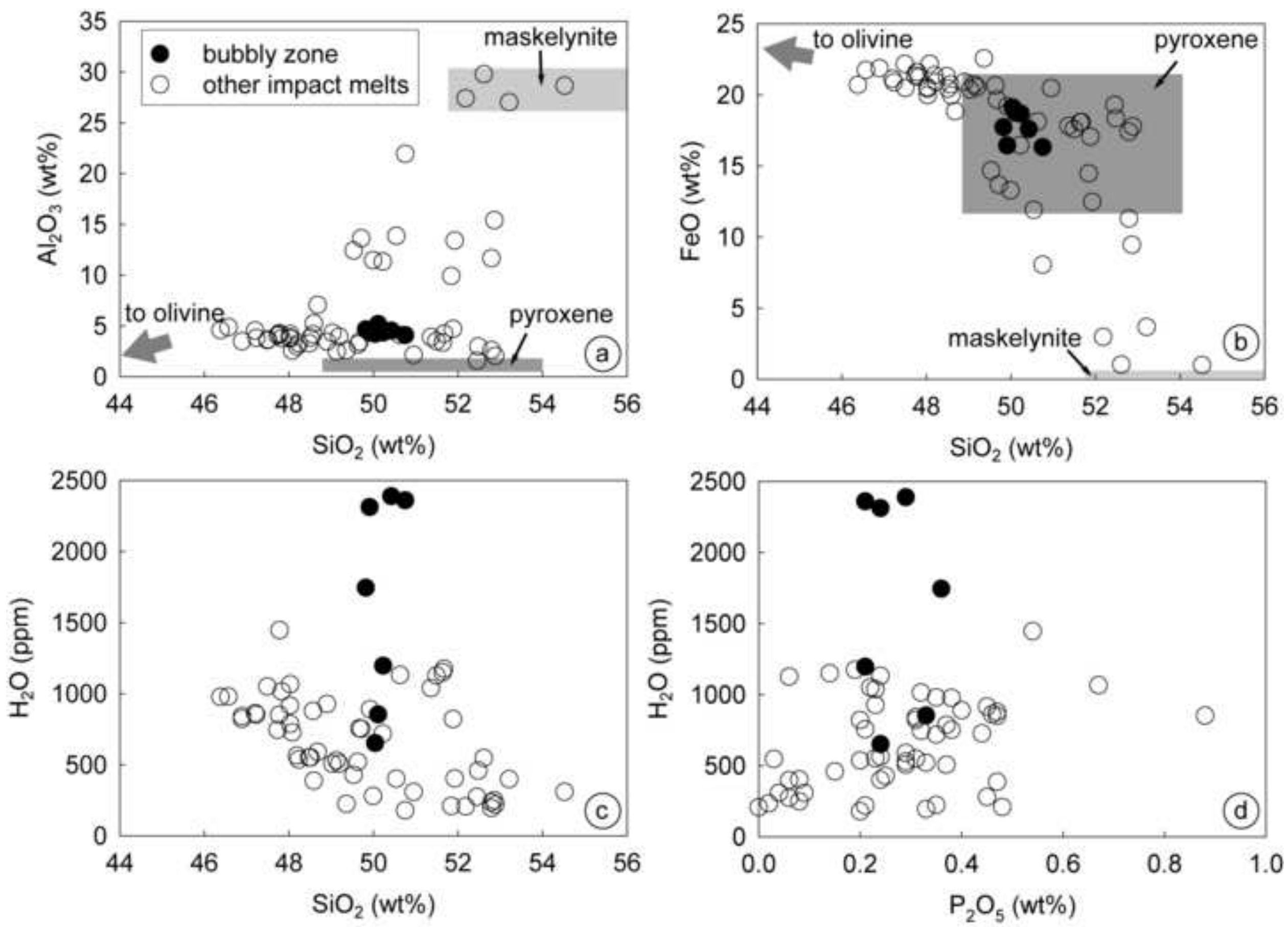

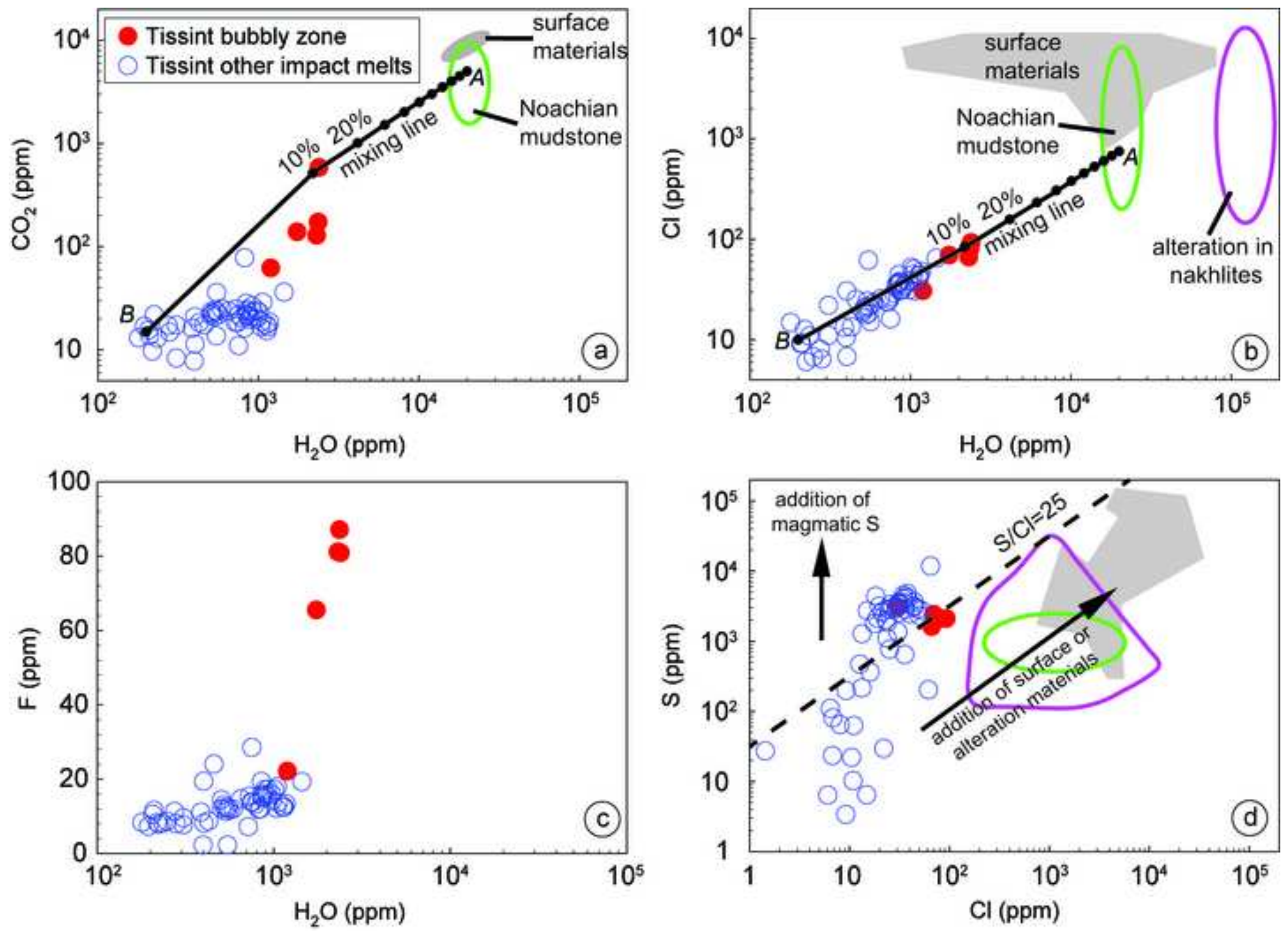


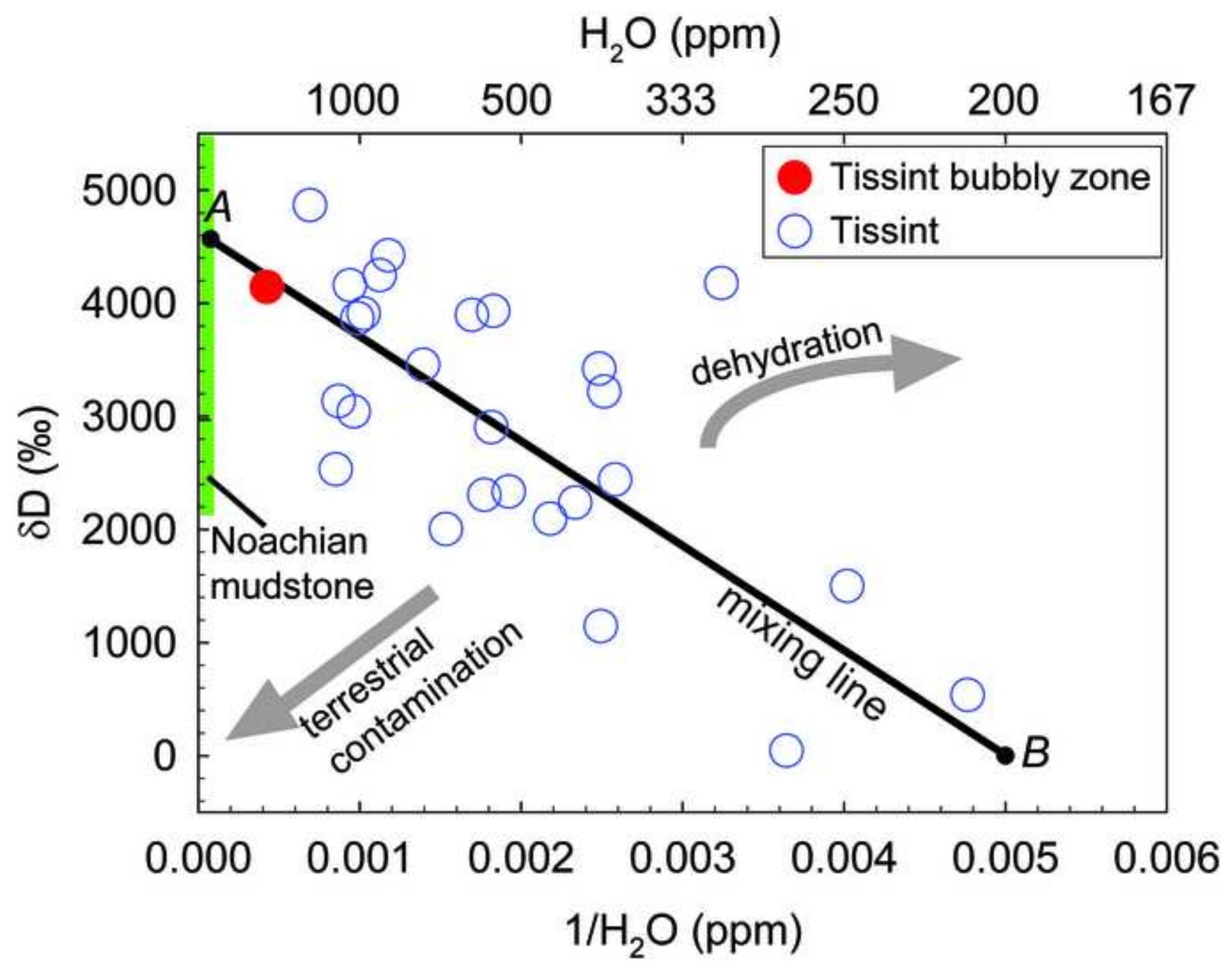



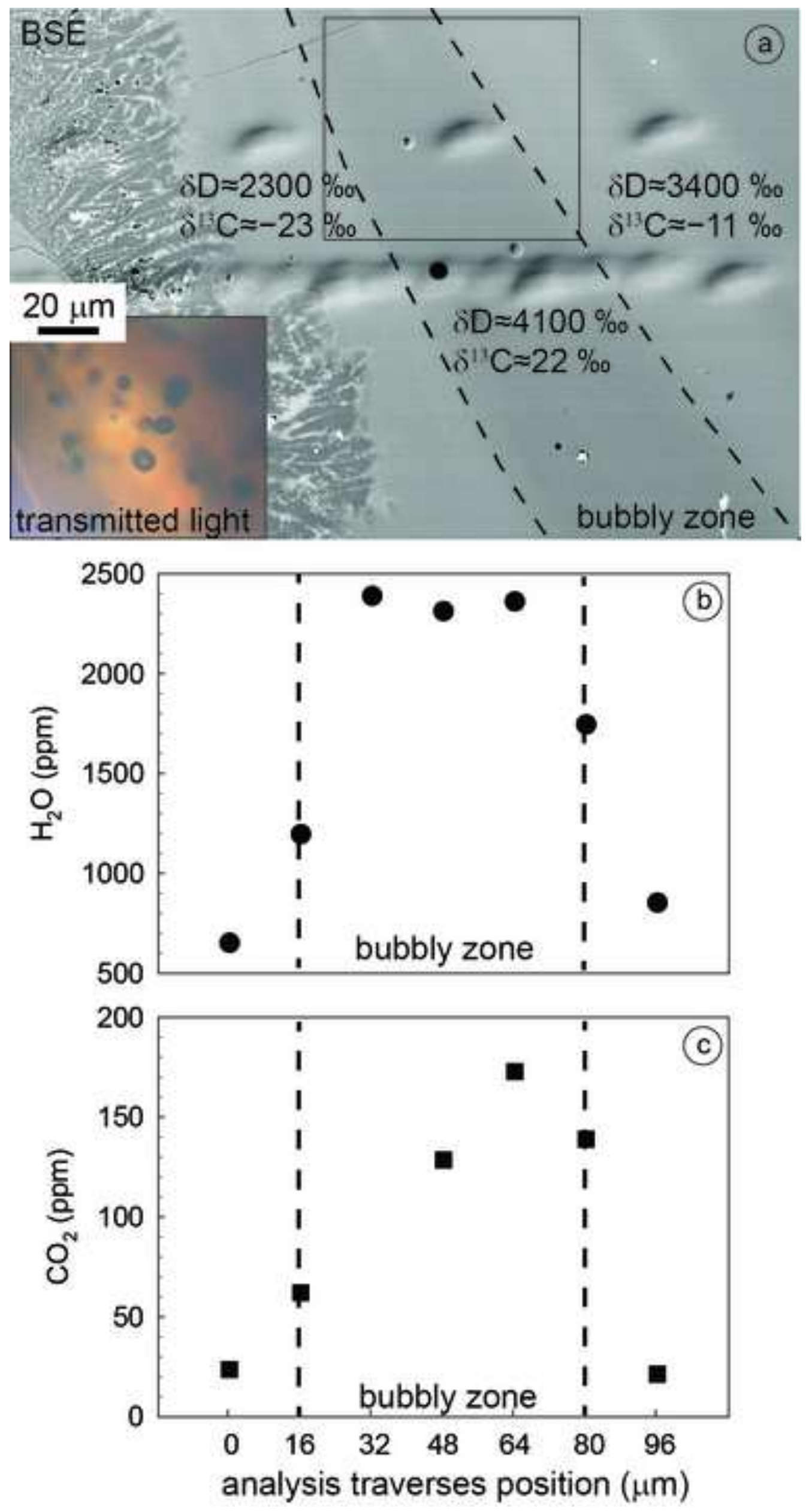


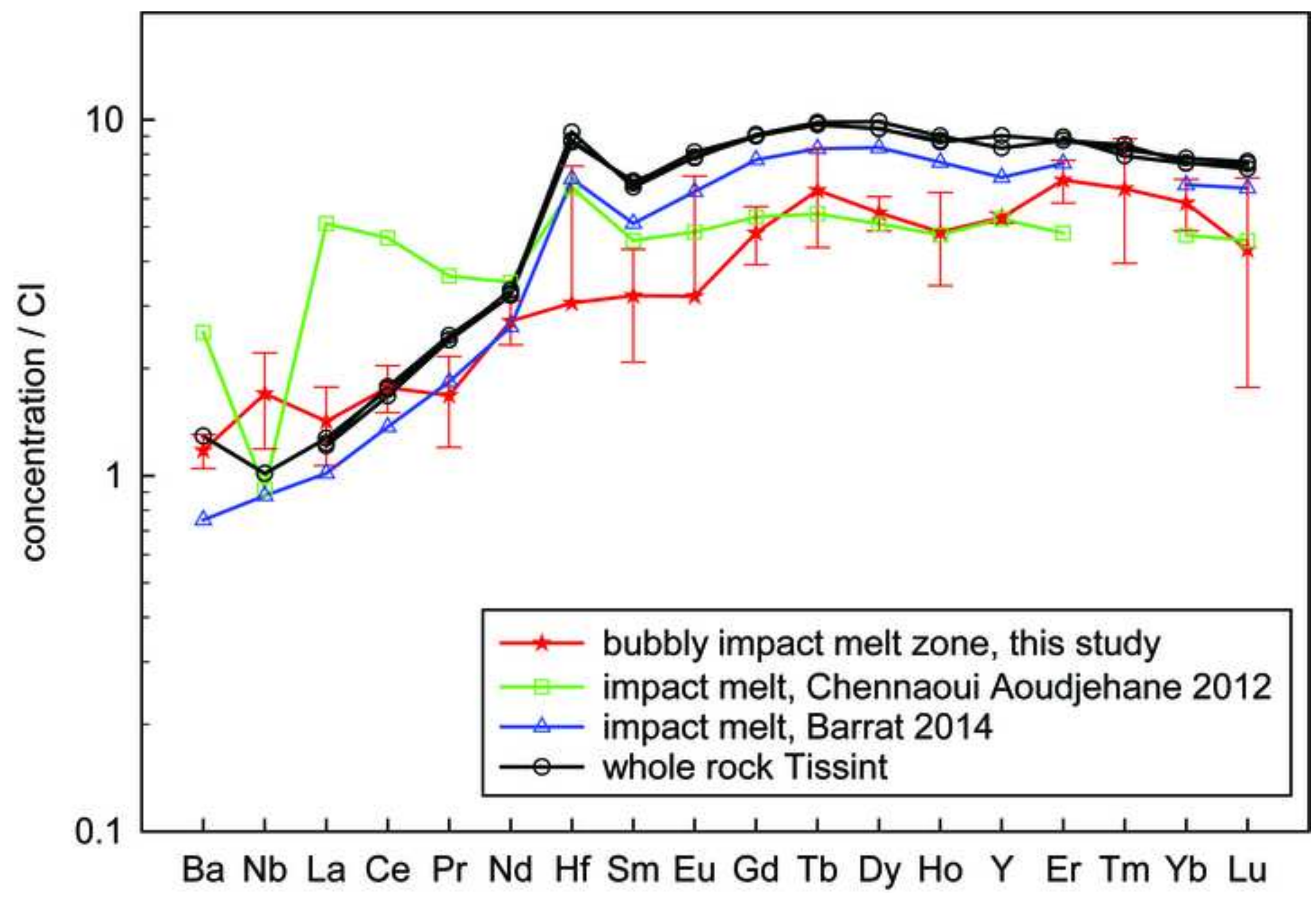



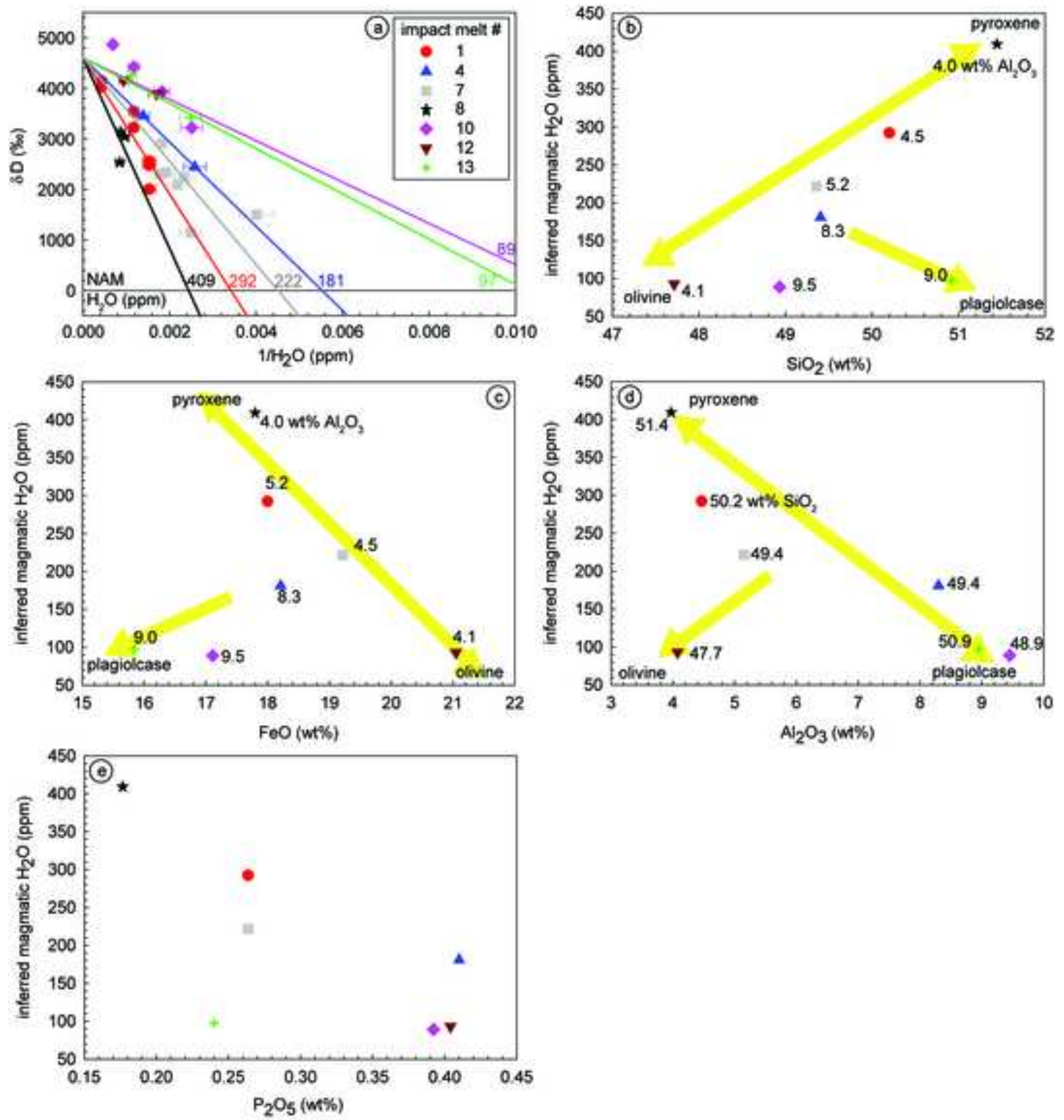